\title{
Efeito da seleção para peso pós-desmame sobre a composição corporal de bovinos $^{1}$
}

\section{Sarah Figueiredo Martins Bonilha², Irineu Umberto Packer ${ }^{3}$, Leopoldo Andrade de Figueiredo², Flávio Dutra de Resende ${ }^{4}$, Guilherme Fernando Alleoni ${ }^{5}$, Alexander George Razook ${ }^{6}$}

\author{
1 Parte da dissertação de Mestrado apresentada à ESALQ/USP pela primeira autora. \\ 2 Instituto de Zootecnia, Centro APTA Bovinos de Corte. \\ ${ }^{3}$ Departamento de Zootecnia da ESALQ/USP. Bolsista do CNPq \\ 4 APTA, PRDTA Alta Mogiana. \\ 5 Instituto de Zootecnia, Sede-Nova Odessa. \\ 6 Instituto de Zootecnia, Centro APTA Bovinos de Corte. Bolsista do CNPq.
}

RESUMO - Foi determinada a composição química corporal no peso de corpo vazio de 56 bovinos machos nãocastrados selecionados ou não para peso aos 378 dias (P378), nascidos em 1999. Utilizaram-se animais dos grupos genéticos Nelore Seleção $(\mathrm{NeS})$, Nelore Controle $(\mathrm{NeC})$ e Caracu Seleção (Ca), distribuídos aleatoriamente em três grupos experimentais: AI - grupo de abate inicial; AR - grupo de alimentação restrita; e AL - grupo de alimentação ad libitum. No grupo de abate inicial, foram utilizados quatro animais por grupo genético e, nas categorias AR e AL, havia oito animais NeS e Ca e seis NeC. Após o período de adaptação, os animais do grupo AI foram abatidos e os demais foram submetidos ao ensaio de alimentação. O período experimental foi determinado pelo tempo de acabamento dos animais do grupo AL, ou seja, quando atingiram $4 \mathrm{~mm}$ de espessura de gordura, avaliada por ultra-som. Em cada grupo genético, à medida que o acabamento preconizado para os animais AL foi atingido, o animal AR com peso e condição corporal mais semelhante a esse no início do experimento também foi abatido. O efeito do grupo genético foi significativo, porém, não houve efeito da interação grupos genéticos $\times$ regimes alimentares sobre a maior parte das características estudadas. A seleção para peso pós-desmame não promoveu alterações indiretas na composição corporal. Animais Ca apresentaram porcentagens menores de gordura e maiores de proteína no corpo vazio, provavelmente em virtude do maior tamanho corporal desses animais.

Palavras-chave: Caracu, composição corporal, Nelore, seleção

\section{Effects of selection for post weaning weight on body composition of beef cattle}

ABSTRACT - Data from 56 bulls of the genetic groups Selection Nellore (NeS), Control Nellore (NeC) and Caracu (Ca) herds born in 1999 were used to evaluate the effects of selection for weight at 378 days of age (P 378) on the chemical composition of empty body weight. The animals were randomly distributed to three experimental classes: initial slaughter (AI), restricted feeding (AR) and ad libitum feeding (AL). The AI class included 4 animals of each genetic group and the AR and AL classes included 8 animals from the NeS and Ca groups and 6 animals from the NeC group. After the adaptation period was finished, animals of the AI class were slaughtered and those from the other classes (AR and AL) started the feeding period which was defined by the time required by the animals of the AL class to reach $4 \mathrm{~mm}$ of fat thickness. Animals of the AR class of all genetic groups were also slaughtered. The selection for post-weaning weight did not promote any change on body composition of the animals. The interaction between genetic group and feeding class was not significant for most of the traits evaluated. The genetic group effect was significant. Lower fat and higher protein percentages of empty body were observed in animals of the genetic group $\mathrm{Ca}$, probably due to their larger mature body size.

Key Words: body composition, Caracu, Nellore, selection

\section{Introdução}

Uma pecuária de corte evoluída visa maximizar, economicamente, o crescimento dos animais. Neste contexto, a determinação da composição corporal é de grande importância em estudos de nutrição que avaliam alimentos ou o crescimento em si. Entretanto, o crescimento é produto de um complexo processo que envolve o ambiente e o potencial genético do animal.

A avaliação do crescimento por meio apenas do ganho de peso limita as conclusões obtidas, pois não envolve a composição química do ganho de peso vazio. O estudo do 
crescimento em relação à taxa de deposição dos constituintes corporais torna possível a utilização de modelos que simulam o desempenho do animal.

A composição química corporal refere-se às porcentagens de EE, proteína, água e cinzas, independentemente dos tecidos em que estão presentes. A presença de carboidratos no corpo do animal é desconsiderada, pois seu teor é baixo e constante, em torno de 0,7\% na MS (Reid et al., 1968). Assim, no cálculo do teor de energia do corpo vazio, são consideradas apenas proteína e gordura, multiplicadas, respectivamente, por 5,641 e 9,343 (Boin, 1995). Além disso, o corpo vazio do animal representa todos os seus tecidos, retirados os conteúdos do trato gastrintestinal e da bexiga e a bílis (Lofgreen \& Garret, 1968), portanto, é consideravelmente diferente da composição da carcaça ou da porção comestível da carcaça.

Para avaliar o desempenho e as exigências nutricionais de zebuínos, vários experimentos foram desenvolvidos utilizando-se animais Nelore não-castrados (Lanna et al., 1995; Boin, 1995), castrados (Leme et al., 1994; Alleoni et al., 1997) e novilhas (Lanna et al., 1999).

No projeto de melhoramento genético da Estação Experimental de Zootecnia de Sertãozinho-SP (EEZS-SP, atual Centro APTA - Bovinos de Corte), tem-se como objetivo principal o aumento da taxa de crescimento dos animais por meio de seleção para peso pós-desmame (Razook et al., 1994; Cyrillo et al., 2000; Cyrillo et al., 2001; Razook et al., 2001a; Razook et al., 2001b). No entanto, até a realização deste estudo, não foram feitas avaliações do efeito da seleção sobre a composição corporal dos animais.

Este trabalho foi realizado com os objetivos de dar continuidade às avaliações de desempenho comparativo em grupos contemporâneos dos rebanhos Nelore e Caracu da EEZS-SP (atual Centro APTA - Bovinos de Corte) selecionados para peso, pertencentes à 19a progênie destas linhas de seleção, e determinar a composição corporal e a taxa de deposição de constituintes químicos nesses animais.

\section{Material e Métodos}

Os animais experimentais foram amostras de machos não-castrados retiradas da $19^{a}$ progênie dos rebanhos Nelore Seleção (NeS) e Caracu (Ca), pertencentes à Estação Experimental do Instituto de Zootecnia de Sertãozinho (atual Centro APTA - Bovinos de Corte), submetidos à seleção com base no peso aos 378 dias de idade (P378), e do rebanho Nelore Controle (NeC), cujos animais apresentavam diferencial de seleção em P378 próximo de zero.
Os animais dos três grupos genéticos foram escolhidos ao término da Prova de Ganho de Peso (PGP) de 2000, segundo regras descritas por Razook et al. (1997), aos 12 meses de idade, obedecendo à média do peso aos 378 dias (P378) de cada rebanho.

Os animais de cada grupo genético foram distribuídos, aleatoriamente, nas três categorias experimentais: AI - grupo de abate inicial; AR - grupo de alimentação restrita; e AL - grupo de alimentação ad libitum. Nos grupos AI, foram alocados quatro animais por grupo genético e, nos grupos AR e AL, oito animais dos grupos NeS e Ca e seis do grupo $\mathrm{NeC}$, totalizando 56 machos.

A fase de confinamento foi realizada na Estação Experimental de Zootecnia de Colina (atual Polo APTA - Alta Mogiana), quando os animais apresentavam, em média, 18 meses de idade e 434, 404 e $345 \mathrm{~kg}$, respectivamente, para os grupos genéticos $\mathrm{Ca}$, $\mathrm{NeS}$ e NeC. No início do experimento, os animais foram pesados e tiveram suas condições corporais avaliadas via ultra-som e escore corporal. Iniciou-se, então, o período de adaptação, no qual todos os animais foram alimentados com a dieta utilizada no grupo ad libitum. Esse período teve duração de 28 dias; logo após, os animais do grupo de abate inicial foram abatidos e os demais foram submetidos ao ensaio de alimentação.

As dietas foram balanceadas com silagem de milho, milho moído, farelo de algodão, uréia, rumensin e mistura mineral e foram reajustadas semanalmente, com base no consumo e na porcentagem de MS do volumoso e do concentrado.

Os animais dos grupos com alimentação restrita e ad libitum foram divididos em pares, de acordo com a semelhança no peso e na condição corporal. Dentro de cada par, sortearam-se dois regimes alimentares: ad libitum alimentação à vontade; e restrito - fornecimento de $65 \mathrm{~g}$ MS/ kg de peso metabólico, procurando suprir as exigências de mantença dos animais. Repetiram-se as pesagens, as medidas de ultra-som e as avaliações de escore corporal a cada 28 dias. Em cada grupo genético, à medida que um animal do grupo AL atingia o acabamento preconizado (mínimo de $4 \mathrm{~mm}$ de espessura de gordura, medida por ultra-som no músculo Longissimus dorsi na posição entre a 12a e a 13a costelas), este era abatido juntamente com seu par do grupo AR.

Os animais foram abatidos aproximadamente aos 22 meses de idade e com pesos vivos médios de: NeS ad libitum - 526,8 kg; NeS restrito - 456,8 kg; NeC ad libitum - 445,0 kg; NeC restrito - 406,0 kg; Ca ad libitum - 562,5 kg; e Ca restrito - 486,5 kg. O abate foi feito no Frigorífico Minerva, localizado na cidade de Barretos-SP, 
e obedeceu ao procedimento normal de um frigorífico sob inspeção federal. O sangue, o fígado, as vísceras e os outros órgãos foram coletados para pesagem e determinação do peso de corpo vazio (PCVZ), calculado como a soma dos pesos de carcaça, sangue, cabeça, couro, patas, cauda, órgãos e vísceras vazias e limpas.

As meias-carcaças foram separadas em quartos dianteiro e traseiro entre a $5 \underline{a}$ e $6 \underline{a}$ costelas e, em seguida, foram pesadas e colocadas em câmara de resfriamento a aproximadamente $2^{\circ} \mathrm{C}$ por 24 horas. Após o resfriamento, os quartos dianteiro e traseiro da meia-carcaça esquerda foram separados em porção comestível e ossos. Após a separação, a porção comestível e os ossos foram acondicionados em sacos plásticos e congelados e a metade esquerda do couro foi picada e resfriada.

A composição corporal dos animais foi feita pela técnica de determinação direta, por meio da moagem de todos os tecidos do animal. Os componentes para moagem foram as metades esquerdas do couro, da cabeça e da carcaça, as patas da meia-carcaça esquerda e todo o tecido gastrintestinal, os outros órgãos e a gordura.

O couro foi moído após resfriamento e os demais componentes, congelados, foram reduzidos a pedaços menores utilizando-se serra. O material serrado foi moído seguidas vezes até ser reduzido a estado pastoso para retirada de quatro amostras de aproximadamente $50 \mathrm{~g}$.

Determinou-se a umidade pela liofilização das amostras, por aproximadamente 80 horas, até atingirem peso constante. Em seguida, as amostras foram reduzidas a pedaços menores e moídas em liquidificador com gelo seco.

O EE foi determinado pela extração com éter dietílico em recipientes de $350 \mathrm{~mL}$ e balões de $500 \mathrm{~mL}$ durante 15 horas. Quatro amostras de $2 \mathrm{~g}$ foram embaladas em papelfiltro para cálculo da quantidade de EE, determinada pela perda de MS da amostra. O teor de cinzas foi determinado pela queima do material em mufla a $600^{\circ} \mathrm{C}$ por 4 horas e o teor de $\mathrm{PB}$, pela diferença entre o peso total da amostra e as quantidades de água, EE e cinzas.

O delineamento experimental foi inteiramente casualizado, com arranjo fatorial $3 \times 2$, composto de três grupos genéticos ( $\mathrm{Ca}, \mathrm{NeS}$ e $\mathrm{NeC}$ ) e dois regimes alimentares (ad libitum e restrito). Utilizou-se análise de variância para testar os efeitos dos grupos genéticos, dos regimes alimentares e da interação e aplicou-se o teste Tukey a 5\% de probabilidade para comparação das médias dos grupos genéticos. Todas as análises de variância foram obtidas pelo PROC GLM do SAS (1999).

\section{Resultados e Discussão}

Não houve efeito da interação regime alimentar $x$ grupo genético sobre as características estudadas, com exceção da porcentagem de cinzas no corpo vazio e da porcentagem de cinzas no ganho de corpo vazio $(\mathrm{P}<0,05)$. Entretanto, o efeito principal de regime alimentar e de grupo genético foi significativo para a maioria das características avaliadas $(\mathrm{P}<0,05)$.

Neste estudo, apenas as diferenças entre $\mathrm{NeS}$ e $\mathrm{NeC}$ podem ser consideradas conseqüência de seleção, uma vez que ambos os rebanhos foram originados da mesma população-base. No rebanho Ca, embora a seleção tenha sido iniciada simultaneamente, houve diferenças raciais, as mais evidentes relacionadas ao tamanho do animal.

Os animais $\mathrm{NeC}$, por apresentarem menor tamanho corporal em relação aos $\mathrm{NeS}$, alcançaram o acabamento de gordura preconizado em menor tempo e foram abatidos mais precocemente, porém, a diferença de nove dias não foi significativa. Os animais desse grupo apresentaram também menores pesos vazios, tanto no início do experimento como no final do período de confinamento (Tabela 1). Os grupos genéticos NeS e Ca não diferiram quanto aos pesos vazios iniciais e finais.

O ganho de peso vazio não diferiu significativamente entre os grupos genéticos (Tabela 2). Animais Ca depositaram menos gordura e mais proteína em comparação aos dos demais grupos genéticos avaliados, no entanto, não foi detectada diferença significativa para deposição de gordura. Animais do grupo $\mathrm{NeC}$ apresentaram diferença significativa quanto à deposição de proteína. Em geral,

Tabela 1 - Tempos de confinamento (dias) e pesos vazios inicial $(\mathrm{kg})$ e final $(\mathrm{kg})$ dos animais Caracu (Ca), Nelore Seleção (NeS) e Nelore Controle (NeC)

Table 1 - Means for feedlot period (days), initial and final empty body weight $(\mathrm{kg})$ of Caracu (Ca), selected Nellore ( $\mathrm{NeS}$ ) and control Nellore ( $\mathrm{NeC}$ ) groups

\begin{tabular}{lcccc}
\hline & \multicolumn{3}{c}{$\begin{array}{c}\text { Grupo } \\
\text { Group }\end{array}$} & CV (\%) \\
\cline { 2 - 4 } & Ca & NeS & NeC & \\
\hline $\begin{array}{l}\text { Tempo de confinamento } \\
\text { Feedlot period }\end{array}$ & $130 \mathrm{a}$ & $115 \mathrm{ab}$ & $104 \mathrm{~b}$ & 21,28 \\
$\begin{array}{l}\text { Peso vazio inicial } \\
\text { Initial empty body weight }\end{array}$ & $343,84 \mathrm{a}$ & $320,09 \mathrm{a}$ & $269,15 \mathrm{~b}$ & 11,1 \\
$\begin{array}{l}\text { Peso vazio final } \\
\text { Final empty body weight }\end{array}$ & $475,00 \mathrm{a}$ & $443,17 \mathrm{a}$ & $383,43 \mathrm{~b}$ & 11,2 \\
\hline
\end{tabular}

Médias com mesma letra nas linhas não diferem $(P<0,05)$ pelo teste Tukey a $5 \%$ de probabilidade.

Means followed by the same letter within a row do not differ $(P<0.05)$ by Tukey test. 
Tabela 2 - Taxas de ganho de peso vazio ( $\mathrm{kg} / \mathrm{dia})$ e constituintes químicos corporais ( $\mathrm{g} / \mathrm{dia}$ ) e de energia (Mcal/dia) em animais Caracu (Ca), Nelore Seleção (NeS) e Nelore Controle $(\mathrm{NeC})$

Table 2 - Means for empty body weight ( $\mathrm{kg} /$ day), chemical body composition ( $\mathrm{g} /$ day) and energy (Mcal/day) gain rate for Caracu (Ca), selected Nellore (NeS) and control Nellore ( $\mathrm{NeC}$ ) groups

\begin{tabular}{|c|c|c|c|c|}
\hline & \multicolumn{3}{|c|}{$\begin{array}{l}\text { Grupo } \\
\text { Group }\end{array}$} & \multirow[t]{2}{*}{ CV (\%) } \\
\hline & $\mathrm{Ca}$ & $\mathrm{NeS}$ & $\mathrm{NeC}$ & \\
\hline $\begin{array}{l}\text { Ganho de peso vazio } \\
\text { Empty body weight gain }\end{array}$ & $1,01 \mathrm{a}$ & $1,00 \mathrm{a}$ & $0,91 \mathrm{a}$ & 19,1 \\
\hline $\begin{array}{l}\text { Água } \\
\text { Water }\end{array}$ & $409 a$ & $355 a$ & $301 \mathrm{a}$ & 33,3 \\
\hline $\begin{array}{l}\text { Gordura } \\
\text { Fat }\end{array}$ & $382 \mathrm{a}$ & $482 \mathrm{a}$ & $457 \mathrm{a}$ & 29,1 \\
\hline $\begin{array}{l}\text { Proteína } \\
\text { Protein }\end{array}$ & $150 \mathrm{a}$ & 113ab & $103 b$ & 40,0 \\
\hline $\begin{array}{l}\text { Cinza } \\
\text { Ash }\end{array}$ & $70 a$ & $46 \mathrm{~b}$ & $52 \mathrm{ab}$ & 38,3 \\
\hline $\begin{array}{l}\text { Energia } \\
\text { Energy }\end{array}$ & $4,45 a$ & 5,19a & $4,91 \mathrm{a}$ & 24,0 \\
\hline
\end{tabular}

Médias com mesma letra nas linhas não diferem $(P<0,05)$ pelo teste Tukey a $5 \%$ de probabilidade.

Means followed by the same letter within a row do not differ $(P<0.05)$ by Tukey test.

estas características apresentaram altos coeficientes de variação.

Quando comparados aos animais Caracu, com base na porcentagem do peso vazio (Tabela 3), animais Nelore apresentaram maior teor de gordura e menor teor de proteína. Os grupos $\mathrm{NeS}$ e NeC não diferiram quanto a essas características, o que pode ser explicado pela diferença no tamanho corporal e no índice de maturidade dos animais. De modo geral, animais em fase de crescimento apresentam menor exigência de energia e maior exigência de proteína por quilo de ganho.

Verificou-se influência da interação regime alimentar $x$ grupo genético sobre a porcentagem de cinzas no corpo vazio. As médias dos grupos genéticos $\mathrm{Ca}, \mathrm{NeS}$ e $\mathrm{NeC}$ no grupo sob alimentação ad libitum foram 3,85; 4,48 e 4,11\% e, no grupo com alimentação restrita, 4,96; 4,71; e 4,07\%, respectivamente. A única diferença entre as médias ocorreu entre grupos genéticos $\mathrm{Ca}$ e $\mathrm{NeC}$, sob alimentação restrita, o que, provavelmente, está relacionado às diferenças na estrutura óssea desses animais.

A porcentagem de minerais encontrada no corpo vazio dos animais dos três grupos genéticos foi semelhante às obtidas por Leme et al. (1994) e Alleoni et al. (1997), que, em experimento com animais Nelore, obtiveram 4,4 e 4,5\%, respectivamente. Esses autores encontraram no corpo vazio 17,9 e $17,1 \%$ de PB e 17,9 e $21,1 \%$ de EE, respectivamente. O teor de água determinado neste estudo foi semelhante ao obtido por Leme et al. (1994), de 59,6\%.
Como demonstrado na Tabela 4, a composição do ganho de corpo vazio foi semelhante entre os grupos $\mathrm{NeS}$ e NeC quanto água, gordura, proteína, cinzas e energia. Os animais Caracu apresentaram menor ganho de energia e gordura e maior ganho de cinzas em comparação aos Nelore.

Observou-se efeito da interação regime alimentar $x$ grupo genético sobre a porcentagem de cinzas no ganho do corpo vazio. As médias dos grupos genéticos $\mathrm{Ca}$, $\mathrm{NeS}$ e NeC com alimentação ad libitum foram 5,04; 4,21 e 5,76\% e, com alimentação restrita, 10,93; 5,32 e 5,83\%, respectivamente. No regime de alimentação restrita, houve diferenças significativas de médias entre os grupos genéticos $\mathrm{Ca}$ e NeS; e Ca e NeC.

Tabela 3 - Composição do corpo vazio (em \%) de animais Caracu (Ca), Nelore Seleção (NeS) e Nelore Controle (NeC)

Table 3 - Means for empty body composition (\%) of Caracu(Ca), selected Nellore (NeS) and control Nellore ( $\mathrm{NeC}$ ) groups

\begin{tabular}{|c|c|c|c|c|}
\hline & \multicolumn{3}{|c|}{$\begin{array}{l}\text { Grupo } \\
\text { Group }\end{array}$} & \multirow[t]{2}{*}{ CV (\%) } \\
\hline & $\mathrm{Ca}$ & $\mathrm{NeS}$ & $\mathrm{NeC}$ & \\
\hline $\begin{array}{l}\text { Água } \\
\text { Water }\end{array}$ & $60,4 a$ & $58,2 b$ & $57,4 b$ & 3,0 \\
\hline $\begin{array}{l}\text { Gordura } \\
\text { Fat }\end{array}$ & $15,5 b$ & $19,4 a$ & $20,2 a$ & 12,1 \\
\hline $\begin{array}{l}\text { Proteína } \\
\text { Protein }\end{array}$ & $19,7 \mathrm{a}$ & $17,8 b$ & $18,3 \mathrm{~b}$ & 5,6 \\
\hline $\begin{array}{l}\text { Cinza } \\
\text { Ash }\end{array}$ & $4,4 \mathrm{ab}$ & $4,6 a$ & $4,1 \mathrm{~b}$ & 11,9 \\
\hline
\end{tabular}

Médias com mesma letra nas linhas não diferem $(P<0,05)$ pelo teste Tukey a $5 \%$ de probabilidade.

Means followed by the same letter within a row do not differ $(P<0.05)$ by Tukey test.

Tabela 4 - Composição do ganho do corpo vazio, em constituintes químicos (\%) e em energia (Mcal/dia), de animais Caracu (Ca), Nelore Seleção (NeS) e Nelore Controle $(\mathrm{NeC})$

Table 4 - Means for chemical components of body gain composition (\%) and energy (Mcal/day) of Caracu (Ca), selected Nellore (NeS) and control Nellore $(\mathrm{NeC})$ groups

\begin{tabular}{lcccc}
\hline & \multicolumn{3}{c}{$\begin{array}{c}\text { Grupo } \\
\text { Group }\end{array}$} & CV (\%) \\
\cline { 2 - 4 } & $\mathrm{Ca}$ & $\mathrm{NeS}$ & $\mathrm{NeC}$ & \\
\hline $\begin{array}{l}\text { Água } \\
\begin{array}{l}\text { Water } \\
\text { Gordura }\end{array}\end{array}$ & $40,1 \mathrm{a}$ & $35,8 \mathrm{a}$ & $32,7 \mathrm{a}$ & 21,9 \\
$\begin{array}{l}\text { Fat } \\
\text { Proteína } \\
\begin{array}{l}\text { Protein } \\
\text { Cinza }\end{array}\end{array}$ & 15,2a & $11,3 \mathrm{a}$ & $12,0 \mathrm{a}$ & 38,6 \\
$\begin{array}{l}\text { Ash } \\
\text { Energia } \\
\text { Energy }\end{array}$ & 4,0a & $4,8 \mathrm{~b}$ & $5,8 \mathrm{ab}$ & 43,7 \\
\hline
\end{tabular}

Médias com mesma letra nas linhas não diferem $(P<0,05)$ pelo teste Tukey a $5 \%$ de probabilidade.

Means followed by the same letter within a row do not differ $(P<0.05)$ by Tukey test. 
Em experimento com tourinhos Santa Gertrudis, Berndt et al. (2002) observaram elevada proporção de gordura (42\%) no ganho de peso vazio, o que pode ser explicado pelo uso de $80 \%$ de concentrado na dieta dos animais.

A composição corporal de animais Nelore, Nelore $\times$ Marchigiana e mestiços leiteiros com sangue Holandês foi estimada por Lanna et al. (1997). As porcentagens finais de gordura encontradas no corpo vazio foram 19, 16 e $18 \%$ respectivamente. Os autores justificam os baixos teores de gordura ao fato de os animais serem machos não-castrados e estarem em crescimento compensatório, apesar de terem sido abatidos com pesos elevados (em torno de $500 \mathrm{~kg}$ ).

Bulle et al. (2002), em estudo com animais $1 / 4$ Bos indicus $\times 3 / 4$ Bos taurus, de raça paterna britânica (Shorthorn) ou continental (Guelbvieh), não encontraram efeito de raça ou de tratamento na composição do ganho de peso vazio. Os animais utilizados apresentaram teores de $28,9 \%$ de gordura e $3,67 \mathrm{mcal} / \mathrm{kg}$ de ganho de peso vazio, valores superiores aos encontrados por Putrino et al. (2006), que, em pesquisa com animais Brangus nãocastrados, obtiveram 22,86\% de gordura e 2,99 mcal/kg de ganho de peso vazio.

Jorge et al. (1999) forneceram alimentação ad libitum ou restrita para tourinhos Gir, Guzerá, Tabapuã e Nelore e não encontraram diferenças entre as raças para as concentrações corporais de proteína, gordura e energia. Os animais abatidos com maiores pesos corporais apresentaram menores porcentagens de proteína e maiores de gordura.

Ferrel \& Jenkins (1998) forneceram alimentação ad libitum ou restrita a novilhos com diferentes combinações maternas e paternas. Os animais alimentados ad libitum foram mais pesados no momento do abate e apresentaram maiores quantidades de água, gordura, proteína, cinzas e energia em comparação aos alimentados com restrição. As taxas de ganho dos componentes do corpo também foram maiores para os animais alimentados à vontade.

Tedeschi et al. (2002) estudaram animais Nelore nãocastrados ou castrados alimentados ad libitum ou com $65 \%$ do consumo ad libitum e relataram que, para os animais não-castrados, não houve diferença significativa entre os tratamentos para porcentagens de água (61,9 e $63,2 \%$ ) e proteína (17,5 e 18,3\%) no ganho de peso vazio. Os teores de proteína obtidos neste estudo foram semelhantes aos encontrados por Putrino et al. (2006) em tourinhos Nelore.

\section{Conclusões}

A seleção para maior peso pós-desmame alterou o potencial de crescimento, mas não provocou grandes diferenças na composição corporal dos animais, ainda que em regimes de terminação distintos.

Animais Caracu, por terem maior tamanho corporal e estarem em estádio de maturidade diferente dos Nelore selecionados e controle, apresentaram porcentagem maior de proteína e menor de gordura no peso vazio.

\section{Literatura Citada}

ALLEONI, G.F.; BOIN, C.; LEME, P.R. et al. Avaliação da gravidade específica e de outras medidas corporais e da carcaça para estimar a composição corporal de novilhos Nelore. Revista Brasileira de Zootecnia, v.26, n.2, p.375-381, 1997.

BERNDT, A.; HENRIQUE, W.; LANNA, D.P.D. et al. Milho úmido, bagaço de cana e silagem de milho em dietas de alto concentrado. Composição corporal e taxas de deposição dos tecidos. Revista Brasileira de Zootecnia, v.31, n.5, p.2105-2112, 2002.

BOIN, C. Alguns dados sobre exigências de energia e de proteína de zebuínos. In: SIMPÓSIO INTERNACIONAL SOBRE EXIGÊNCIAS NUTRICIONAIS DE RUMINANTES, 1., 1995 , Viçosa, MG. Anais... Viçosa, MG: Universidade Federal de Viçosa, 1995. p.457-465.

BULlE, M.L.M.; RIBEIRO, F.G.; LEME, P.R. et al. Exigências líquidas de energia e proteína de tourinhos de dois grupos genéticos alimentados com dietas de alto teor de concentrado. Revista Brasileira de Zootecnia, v.31, n.1, p.436-443, 2002.

CYRILLO, J.N.S.G.; RAZOOK, A.G.; FIGUEIREDO, L.A. et al. Efeitos da seleção para peso pós desmame sobre medidas corporais e perímetro escrotal de machos Nelore de Sertãozinho. Revista Brasileira de Zootecnia, v.29, n.2, p.403-412, 2000.

CYRILLO, J.N.S.G.; RAZOOK, A.G.; FIGUEIREDO, L.A. et al. Estimativas de tendências e parâmetros genéticos do peso padronizado aos 378 dias de idade, medidas corporais e perímetro escrotal de machos Nelore de Sertãozinho, SP. Revista Brasileira de Zootecnia, v.30, n.1, p.56-65, 2001.

FERREL, C.L.; JENKINS, T.G. Body composition and energy utilization by steers of diverse genotypes fed a high-concentrate diet during the finish period: I Angus, Belgian Bleu, Hereford and Piedmontese Sires. Journal of Animal Science, v.76, n.2, p.637-646, 1998.

JORGE, A.M.; FONTES, C.A.A.; PAUlinO, M.F. Composição corporal de bovinos de quatro raças zebuínas, abatidos em diferentes estádios de maturidade. Revista Brasileira de Zootecnia, v.28, n.2, p.388-394, 1999.

LANNA, D.P.D.; BOIN, C.; ALLEONI, G.F. et al Estimativa da composição química corporal de tourinhos Nelore através da gravidade específica. Revista Brasileira de Zootecnia, v.24, n.3, p.351-359, 1995.

LANNA, D.P.D.; LEME, P.R.; BOIN, C. et al. Ganho compensatório de bovinos de diferentes grupos genéticos: composição química e física corporal. In: REUNIÃO ANUAL DA SOCIEDADE BRASILEIRA DE ZOOTECNIA, 34., 1997, Juiz de Fora. Anais... Juiz de Fora: Sociedade Brasileira de Zootecnia, 1997. p.352-354.

LANNA, D.P.L.; MORAIS, J.P.; BOIN, C. et al. Desempenho e composição corporal de novilhas alimentadas com dois níveis de concentrado e bagaço de cana submetido a diferentes processos de hidrólise. Revista Brasileira de Zootecnia, v.28, n.2, p.412-420, 1999.

LEME, P.R.; BOIN, C.; ALLEONI, G.F. et al. Estimativa da composição química corporal de novilhos Nelore através do espaço de deutério. Revista Brasileira de Zootecnia, v.26, n.3, p.351-362, 1994.

LOFGREEN, G.P.; GARRET, W.N. A system for expressing net energy requeriments and feed values for growing and finish beef cattle. Journal of Animal Science, v.27, n.3, p.793-806, 1968. 
PUTRINO, S.M.; LEME, P.R.; SILVA, S.L. et al. Exigências líquidas de proteína e energia para ganho de peso de tourinhos Brangus e Nelore alimentados com dietas contendo diferentes proporções de concentrado. Revista Brasileira de Zootecnia, v.35, n.1, p.292-300, 2006.

RAZOOK, A.G.; FIGUEIREDO, L.A.; BONILHA NETO, L.M. Diferenças observadas em progênies de touros Nelore testados em prova de ganho de peso e com diferenciais de seleção nulo ou positivo para o peso pós desmama, em um rebanho PO. Boletim de Indústria Animal, v.51, n.1, p.87-98, 1994.

RAZOOK, A.G.; FIGUEIREDO, L.A.; CYRILLO, J.N.S.G. et al. Prova de ganho de peso: normas adotadas pela Estação Experimental de Zootecnia de Sertãozinho. Nova Odessa: Instituto de Zootecnia, 1997. 42p. (Boletim Técnico, 40).

RAZOOK, A.G.; FIGUEIREDO, L.A.; NARDON, R.F. et al. Efeitos de raça e da seleção para peso pós-desmame sobre características de confinamento e de carcaça da $15^{a}$ progênie dos rebanhos Zebu e Caracu de Sertãozinho (SP). Revista Brasileira de Zootecnia, v.30, n.1, p.115-124, 2001a.
RAZOOK, A.G.; NARDON, R.F.; TEDESCHI, L.O. et al. Estimativas da composição física das carcaças e do corpo vazio de amostras da $15^{\mathrm{a}}$ progênie dos rebanhos Zebu e Caracu de Sertãozinho (SP). Revista Brasileira de Zootecnia, v.30, n.3, p.10371043, 2001b.

REID, J.T.; BENSADOUN, A.; BULL, L.S. et al. Some peculiarities in the body composition of animals. In: NATIONAL ACADEMY OF SCIENCES, 1968, Columbia. Proceedings... Columbia: University of Missouri, 1968. p.19-44.

STATISTICAL ANALYSIS SYSTEM - SAS. [1999]. SAS online doc: version 8. Disponível em: <http://www.id.unizh.ch/software/ unix/statmath/sas/sasdoc/stat/index.htm.> Acesso em: 10/3/2005.

TEDESCHI, L.O.; BOIN, C.; FOX, D.G. et al. Energy requirement for maintenance and growth of Nellore bulls and steers fed high-forage diets. Journal of Animal Science, v.80, n.6, p.1671-1682, 2002.

Recebido: 10/8/2005 Aprovado: 9/4/2007 